University of Nebraska - Lincoln

DigitalCommons@University of Nebraska - Lincoln

Faculty Publications, Department of Psychology

Psychology, Department of

2006

Identity Orientation, Voice, and Judgments of Procedural Justice During Late Adolescence

\author{
Mark R. Fondacaro \\ City University of New York, mfondacaro@jjay.cuny.edu \\ Eve M. Brank \\ University of Nebraska-Lincoln, ebrank2@unl.edu \\ Jennifer Stuart \\ University of Florida \\ Sara Villanueva-Abraham \\ University of Florida \\ Jennifer Luescher \\ University of Florida \\ See next page for additional authors
}

Follow this and additional works at: https://digitalcommons.unl.edu/psychfacpub

Part of the Psychiatry and Psychology Commons

Fondacaro, Mark R.; Brank, Eve M.; Stuart, Jennifer; Villanueva-Abraham, Sara; Luescher, Jennifer; and McNatt, Penny S., "Identity Orientation, Voice, and Judgments of Procedural Justice During Late Adolescence" (2006). Faculty Publications, Department of Psychology. 391.

https://digitalcommons.unl.edu/psychfacpub/391

This Article is brought to you for free and open access by the Psychology, Department of at DigitalCommons@University of Nebraska - Lincoln. It has been accepted for inclusion in Faculty Publications, Department of Psychology by an authorized administrator of DigitalCommons@University of Nebraska - Lincoln. 


\section{Authors}

Mark R. Fondacaro, Eve M. Brank, Jennifer Stuart, Sara Villanueva-Abraham, Jennifer Luescher, and Penny S. McNatt 


\title{
Identity Orientation, Voice, and Judgments of Procedural Jus- tice During Late Adolescence
}

\author{
Mark R. Fondacaro ${ }^{1}$, Eve M. Brank ${ }^{2}$, Jennifer Stuart ${ }^{3}$, Sara Villanueva-Abraham ${ }^{4}$, \\ Jennifer Luescher ${ }^{5}$ and Penny S. McNatt ${ }^{6}$
}

Received January 31, 2005; accepted June 14, 2005; published online May 13, 2006

\begin{abstract}
This study focused on the relationship between voice and judgments of procedural justice in a sample of older adolescents and examined potential moderating and mediating influences of identity orientation (personal, social, and collective) and negative emotional response. Participants read 1 of two different family conflict scenarios (voice and no voice) asking them to imagine themselves in a disagreement with their parents over grades and financial support. In the voice condition, parents were described as making their decision after listening to the participant's input. In the no voice condition, parents were described as making their decision without listening to the participant's input. The adolescents then judged the fairness of the parental decisions and responded to questions concerning their identity orientation. Findings indicate that in addition to replicating the effect of voice in a novel context, the present investigation found moderating effects of personal identity orientation on procedural fairness judgments. Additionally, negative emotional response partially mediated the relationship between voice and global judgments of procedural fairness.
\end{abstract}

Key words: identity; procedural justice; voice; family conflict; older adolescents.

${ }^{1}$ Mark R. Fondacaro is an Associate Professor of Psychology and Associate Director of the Levin College of Law Center on Children and Families at the University of Florida. He received his Ph.D. in clinical psychology from Indiana University and his J.D. from Columbia University School of Law. His major research interests are ecological jurisprudence and the conceptualization and assessment of procedural justice in legal and extra-legal contexts including the family and the juvenile justice and health care systems.

${ }^{2}$ Eve M. Brank, now at the University of Nebraska-Lincoln, was an Assistant Professor of Criminology, Law \& Society at the University of Florida. She received her Ph.D. in social psychology and her J.D. from the University of NebraskaLincoln. Her major research interests are parental responsibility laws and juvenile law issues.

3Jennifer Stuart is a graduate student in counseling psychol-

Introduction

Justice, a concept most often associated with the legal system and with society in general, is increasingly being studied in the family context (Fondacaro et al., 1998, 2002; Jackson and Fondacaro, 1999). The concept of justice is typically divided into 2 constructs: procedural justice and distributive justice. While distribu- ogy at the University of Florida. Her major research interests are adolescent development and delinquency prevention. ${ }^{4}$ Sara Villanueva-Abraham received her Ph.D. in developmental psychology from the University of Florida. Her major research interests are adolescent development and parentchild relationships.

${ }^{5}$ Jennifer Luescher is a Forensic Psychology Postdoctoral Fellow at the University of Massachusetts, Boston. She received her Ph.D. in counseling psychology from the University of Florida. Her major research interests are in the areas of procedural justice, risk assessment and risk management, and mental health and juvenile justice policy.

${ }^{6}$ Penny S. McNatt is a Visiting Assistant Professor at the University of North Florida. She received her Ph.D. in social psychology from the University of Florida. Her major research interests are in the area of intergroup relations. tive justice refers to the fairness of a decision's outcome, procedural justice refers to the fairness of the procedures used to arrive at the decision. Procedural justice, or the way adolescents feel their parents handle important decision-making processes, has been established as an important component of conflict resolution within the family (Fondacaro et al., 1998).

There is an emerging consensus that unlike distribu- 
tive justice principles, which appear to be highly culture-specific, principles of procedural justice may be more universal (Tyler et al., 1997). One fairly consistent finding in the procedural justice literature is the importance of "voice" or participation in decision making as 1 of several criteria that people use to evaluate procedural fairness (Fondacaro et al., 2002; Lind and Tyler, 1988; Thibaut and Walker, 1975). Individuals from varied backgrounds and across diverse contexts (e.g., legal, family, health care) are more likely to evaluate a decision-making process as fair if they have voice and are allowed to participate in decision making. The purpose of this study is to examine the relationship between voice and judgments of procedural justice in resolving informal family disputes in an ethnically diverse sample of older adolescents. We will also examine the potential moderating and mediating influences of identity orientation and anger arousal, respectively, on the relationship between voice and global appraisals of procedural justice.

\section{Family Conflict}

Adolescence is a time of transition from childhood roles to more independent, adult roles. With this increased push for autonomy often comes an increased level of conflict, particularly with family members. While disagreements may seem to be a commonplace occurrence in families with adolescents, the ways in which these disagreements are resolved are far from universal (Jackson and Fondacaro, 1999). The manner in which family conflicts are resolved has important implications for family functioning and for adolescents' social and emotional development.

Adolescents whose parents treat them in a neutral and trustworthy manner during family disputes report higher levels of family cohesion, lower levels of family conflict, and lower levels of deviant behavior (Fondacaro et al., 1998). On the other hand, unfair treatment during the resolution of a conflict is likely to lead to resentment and anger by adolescents, which can fuel ongoing levels of family conflict (Fondacaro and Heller, 1990). Increases in conflict and decreases in support can make the already challenging transition from adolescence to adulthood even more difficult (Fondacaro et al., 1998).

Research by Fondacaro et al. (1998) focused specifically on the unique challenges facing older adolescents (aged 18-22 years), including the gradual increase in independence coupled with the maintenance of close family ties. They found that older adolescents whose parents resolved disputes in a more neutral, trustworthy, and respectful manner experienced higher levels of family cohesion and lower levels of family conflict. Low levels of procedural justice in family disputes were also linked to deviant behavior and psychological distress. The fair resolution of family conflict may be especially important during this transitional time while adolescents are negotiating new and complex roles within the family.

\section{The "Voice Effect"}

Beginning with studies of disputants' satisfaction in adversary versus nonadversary legal procedures, Thibaut and Walker (1975) introduced the idea that people care not only about the outcome of a decision, but also about the process of decision making. In this seminal work, Thibaut and Walker proposed that if disputants were provided with the opportunity to voice their opinions, they would be more likely to view the decision-making process as fair and just. The simple ability to state one's claim and have some control in the decision-making process was the foundation of this new definition of justice (Thibaut and Walker, 1975). This early work proved to be of great heuristic value for several reasons. First, it demonstrated that the use of fair decision-making procedures is one mechanism through which conflicting parties may come to accept an outcome (Tyler and Lind, 2001). Second, this line of research provided the first empirical demonstration that, regardless of outcome, differences in procedures produced different judgments of fairness. Despite its vast importance and influence, the Thibaut and Walker research was limited to laboratory studies, as well as to legal decision-making scenarios.

Leventhal (1980) expanded the basic Thibaut and Walker inquiry by examining a broader theoretical approach to the procedural justice framework. He outlined 6 structural components that every procedure should have (1) consistency; (2) suppression of biases; (3) accuracy of information; (4) correctibility; (5) representation or voice; and (6) ethicality. Each of these components has led to various forms of research (Lind and Tyler, 1988). The formal, structural approach used by Thibaut and Walker (1975) and the theoretical approach of Leventhal (1980) gradually evolved to include a wider range of formal and informal procedures. Researchers tested the foundation of procedural justice theory in a variety of settings including citizen experiences with the police and courts (Tyler, 1984, 1988; Tyler and Folger, 1980), simulated trials (Lind, 1980), evaluations of teachers or political leaders (Tyler and Caine, 1981), employment decisions (Folger and Konovsky, 1989), preferences for adversary and nonadversary dispute resolution procedures (Leung and 
Lind, 1986), litigation procedures (Poythress et al., 1993), employee attitudes toward drug testing (Konovsky and Cropanzano, 1991), and organizational change (Korsgaard et al., 1980). In this body of research, the desire for voice consistently emerged as an important factor in fairness judgments.

\section{Identity Orientation}

Clearly, voice is a salient ingredient of global appraisals of procedural justice across many contexts. It is therefore important to determine what may affect the relationship between voice and procedural justice appraisals. As Brockner et al. (1998) noted, moderating influences on voice have mostly been studied in the form of situational factors. Some research, however, has focused on the moderating influences of personal characteristics, such as self-esteem (Brockner et al., 1998). Drawing on this work and other research calling for a more concerted effort to examine how issues of identity influence justice judgments in various contexts (Clayton and Opotow, 2003), the current research examines the moderating influence of the personal characteristic of identity orientation on the relationship between voice and procedural fairness judgments in the context of informal family disputes.

Identity is a particularly salient construct in the life of an adolescent. According to Erikson (1959), one of the chief tasks of the adolescent time period is constructing one's own identity. Marcia (1980) describes identity as "an internal, self-constructed, dynamic organization of drives, abilities, beliefs, and individual history." He describes a model of identity formation made up of 4 statuses: identity diffusion, foreclosure, moratorium, and identity achievement. These statuses represent different styles of resolution of the identity issues encountered by all individuals. While there are both healthy and unhealthy aspects of identity diffusion, foreclosure, and moratorium, those who have reached identity achievement have experienced a decision-making period and are now pursuing self-chosen goals. Research has widely supported the notion that adolescence is a time when individuals move from an immature or parentally determined identity toward a solid, self-selected identity. Late adolescence, in particular, is a crucial time period for identity formation. According to Meilman (1977), most individuals shift from identity diffusion or foreclosure to identity achievement status between 18 and 21 years of age. Matteson (1975) commented on college specifically, asserting that the move away from home as a factor that induces an "identity crisis," encouraging adolescents to explore and commit to an identity.
While it is widely acknowledged that identity formation is an important task in the life of an adolescent, less is known about the impact of specific identity orientations on other aspects of an adolescent's life. Identity orientation is traditionally thought of as a multidimensional construct with facets encompassing who we are and where we place ourselves in the world (Clayton and Opotow, 2003). It involves the individual and the individual in relation to the rest of the world. The idea of differing identity orientations refers to the relative importance that individuals place on various identity characteristics when constructing their self-definitions (Cheek and Tropp, 1994). Personal identity or individual identity, as it is sometimes called, reflects the extent to which identity is tied to more personal, individualistic notions or beliefs (Clayton and Opotow, 2003). More specifically, personal identity is one's private conception of self and feelings of continuity and uniqueness. Personal identity is reflected through personal goals, values, and feelings (Cheek and Tropp, 1994).

Clayton and Opotow (2003) make the claim that, "[i] dentity affects why people care about justice" (p. 301). Whereas distributive justice examines the "what," and procedural justice examines the "how," Clayton and Opotow argue that adding identity theory will finally examine the "who" in justice literature. Including identity into the mix provides justice theory with the ability to address the more complex reactions to procedural justice issues. Similarly, Skitka (2003) links justice reasoning with self-concept in the development of the Accessible Identity Model (AIM). The AIM uses James' (1890) material, social, and personal identity orientations. In the AIM, the individual's perception of fairness depends on which identity is most salient or most cognitively accessible. Skitka notes that most research has focused on the salience of social identity (e.g., Tyler and Blader, 2003), rather than personal or material identity, as a moderator of procedural fairness judgments. Current theories hold that procedural actions communicate important information to the individual about his/her place in the group. Skitka (2002) argues that rather than being motivated solely by the interest of social status, individuals care about procedural justice because of a need to maintain a positive personal identity. People work to maintain positive self-appraisals because negative self-appraisals can lead to negative mental health consequences such as anxiety and depression. Personal identity becomes especially salient when individuals are pursuing an achievement goal or when moral values are threatened (Skitka, 2003). When the personal identity orientation is the most accessible, reactions to procedural unfairness, such as a lack of voice, may be especially relevant. 
Negative Emotional Response and Procedural Justice

In contrast to the identity orientation of the parties involved in a dispute, an emotional response is much more variable. Whereas the identity orientation cannot directly and immediately be influenced by the dispute resolution process, an emotional response can occur as a direct response to the procedures followed. For this reason, emotional response makes an appropriate contrast to the effects of the personal characteristics discussed previously.

Certainly, other researchers have addressed emotional factors in justice judgments (Tyler, 1994). However, most of the justice research that has focused on emotional response has focused on considerations of distributive justice and outcome fairness (e.g., Mikula et al., 1998). Increasingly, justice researchers interested in emotional response are taking a more comprehensive, integrative approach. For instance, Krehbiel and Cropanzano (2000) examined emotional response in relation to both procedural fairness and outcome favorability. They found that negative emotions such as anger and frustration were highest when their participants found themselves in an unfair process, receiving an unfavorable outcome. Other recent research suggests that attention to issues of negative emotions such as anger may be particularly important in the emotionally charged setting of the family, especially the family with an adolescent (Fondacaro et al., 1998, 2002).

This study draws on a diverse sample of African American, Asian American, European American, and Hispanic American older adolescents and examines the moderating influence of personal identity orientation on the relationship between voice and procedural fairness judgments. We also examine the mediating influence of negative emotional response on the relationship between voice and global appraisals of procedural fairness.

\section{Hypotheses}

a. The present investigation will replicate the "voice effect," this time within the informal context of family decision making by finding a main effect of voice on perceptions of fairness.

b. Similar to the association with self-esteem (Brockner et al., 1998), the association between voice and perceptions of procedural fairness will be moderated by identity orientation. Specifically, on the basis of Skitka's (2002) work, it is expected that in an achievement-oriented context, personal identity orientation (rather than social or community) will moderate the relationship between voice and procedural fairness.

c. Expanding on existing emotional response research, we predict that the relationship between voice and procedural fairness will be mediated by negative emotional response.

Method

Participants

Participants were 283 undergraduates at the University of Florida in Gainesville. All participants met the criterion for late adolescence defined as being between the ages of 18 and 22 years (see Elliott and Feldman, 1990). Of these participants, $66.4 \%$ were females and $33.6 \%$ were males. The mean age of the participants was $18.71(\mathrm{SD}=0.86)$ with $72.4 \%$ of them having parents who were married. All of the participants reported that they had never been married themselves. Participants came from diverse ethnic backgrounds with 30.7\% European American, 20.5\% African American, 24\% Hispanic American, and 24.7\% Asian American. All the participants were treated in accordance with the "Ethical Principles of Psychologists and Code of Conduct" (American Psychological Association, 1992).

\section{Measures}

Before beginning the study, participants were asked about their gender, age, year in school, marital status, parents' marital status, and a series of ethnicityand culture-related questions. Following the collection of demographic information, participants were presented with the following measures.

\section{The Conflict Scenario}

The participants read 1 of 2 different family conflict scenarios. Both scenarios began by instructing the participants to imagine themselves in the described situation. The situation involved a disagreement between a college student and his/her parents over grades and financial support. In the "voice" conflict scenario, the parents are described as making their decision after listening to their son's or daughter's arguments. In contrast, the "no voice" conflict scenario describes the parents as making their decision without listening to their son's or daughter's arguments (see Appendix A). Approximately, equal number of participants received each version of the scenario (voice: $n=143$; no voice: $n$ $=140)$. 


\section{Family Decision-Making Questionnaire}

Following the conflict scenario, participants completed the Family Decision-Making Questionnaire (FDMQ) developed by Fondacaro et al. (2002).Of particular relevance to the current research is the Global Procedural Fairness (GPF) subscale (which served as one of the primary dependent variables) and the Voice subscale (which served as a manipulation check for the experimental manipulation) (see Appendix B). The GPF measure $(a=0.92, \mathrm{M}=3.73, \mathrm{SD}=0.85)$ included 6 Likert-scale questions (e.g., "Overall, you were treated fairly"), each on a 5-point scale ranging from 1 (strongly disagree) to 5 (strongly agree). The voice subscale $(a=0.91, \mathrm{M}=3.4, \mathrm{SD}=1.01)$ included 6 questions (e.g., "Your parent(s) asked for your input before a decision was made").

\section{Aspects of Identity Questionnaire}

Participants also answered a series of questions developed by Cheek, Tropp, and colleagues referred to as the Aspects of Identity Questionnaire (AIQ-IIIx) (Cheek and Tropp, 1994). The AIQ-IIIx included a total of 34 Likert-scale questions related to personal identity (PI), social identity (SI), or collective identity (CI). Personal identity was characterized by items related to individual values, thoughts, and characteristics without comparison to outside reference groups. Social identity was characterized by items related to status, reputation, and social roles relative to others. Collective identity was characterized by items related to a sense of a belonging within a larger group such as race, religion, or community. Participants indicated how important a series of questions was to their sense of who they were. Internal scale consistency was high for all three identity subscales (PI: $a=0.86, \mathrm{M}=4.3$, SD $=0.54 ; \mathrm{SI}: a=0.83, \mathrm{M}=3.4, \mathrm{SD}=0.72$; and CI: $a=0.79$, $\mathrm{M}=3.3, \mathrm{SD}=0.69$ ).

\section{Negative Emotional Response}

Participants answered 7 questions related to their emotional response to the way their parents would have made them feel in the described situation. Questions concerning emotional response were based on questions used in the Health Care Justice Inventory (HCJI) reported by Murphy-Berman et al. (1999). Emotions presented in these questions were either positive (pleased and proud) or negative (angry, sad, embarrassed, ashamed, and depressed) and participants indicated their agreement level on a 5-point scale. For instance, the first question asked for an agreement rating (from 1 for strongly disagree to 5 for strongly agree) for the following statement, "The way my parents treated me made me feel angry." An overall emotional response score was computed by first reverse coding the 2 positive emotional response questions and then taking the mean agreement rating across the 7 emotional responses. The resulting subscale was therefore a measure of negative emotional response with higher values indicating greater emotional response. Internal consistency was quite high $(a=0.92, \mathrm{M}=2.54, \mathrm{SD}=$ 1.1).

Because much of the existing theoretical framework for this study deals specifically with anger arousal, analyses were also conducted using only the anger arousal item. Results were still significant and essentially the same. Results using the 7 item negative emotional response scale are presented here to ensure higher reliability.

Results

Voice Manipulation Check

An independent samples t-test revealed a significant effect of the voice manipulation, $t(281)=-8.12, p$ $<0.001$. Participants who received the voice scenario scored significantly higher on the voice subscale of the FDMQ $(\mathrm{M}=3.86, \mathrm{SD}=0.76)$ than those who received the no voice scenario $(\mathrm{M}=2.98, \mathrm{SD}=1.05)$. This indicates that participants viewed their parents as providing a greater opportunity for input in the voice condition than the no voice condition.

\section{Global Procedural Fairness}

An independent samples t-test revealed a significant effect of voice on ratings of global procedural fairness, $t(281)=-5.67, p<0.001$. Participants who received the voice scenario gave higher ratings of global procedural fairness $(M=4.01, S D=0.69)$ than did the participants who received the no voice scenario $(\mathrm{M}=3.46$, $\mathrm{SD}=0.91)$.

Relationships Among Voice, Negative Emotional Response, and Global Procedural Fairness

Pearson's correlation revealed a significant negative correlation between participants' ratings of opportunity to provide input (voice subscale) and negative emotional response, $r(279)=-0.65, p<0.001$. This 


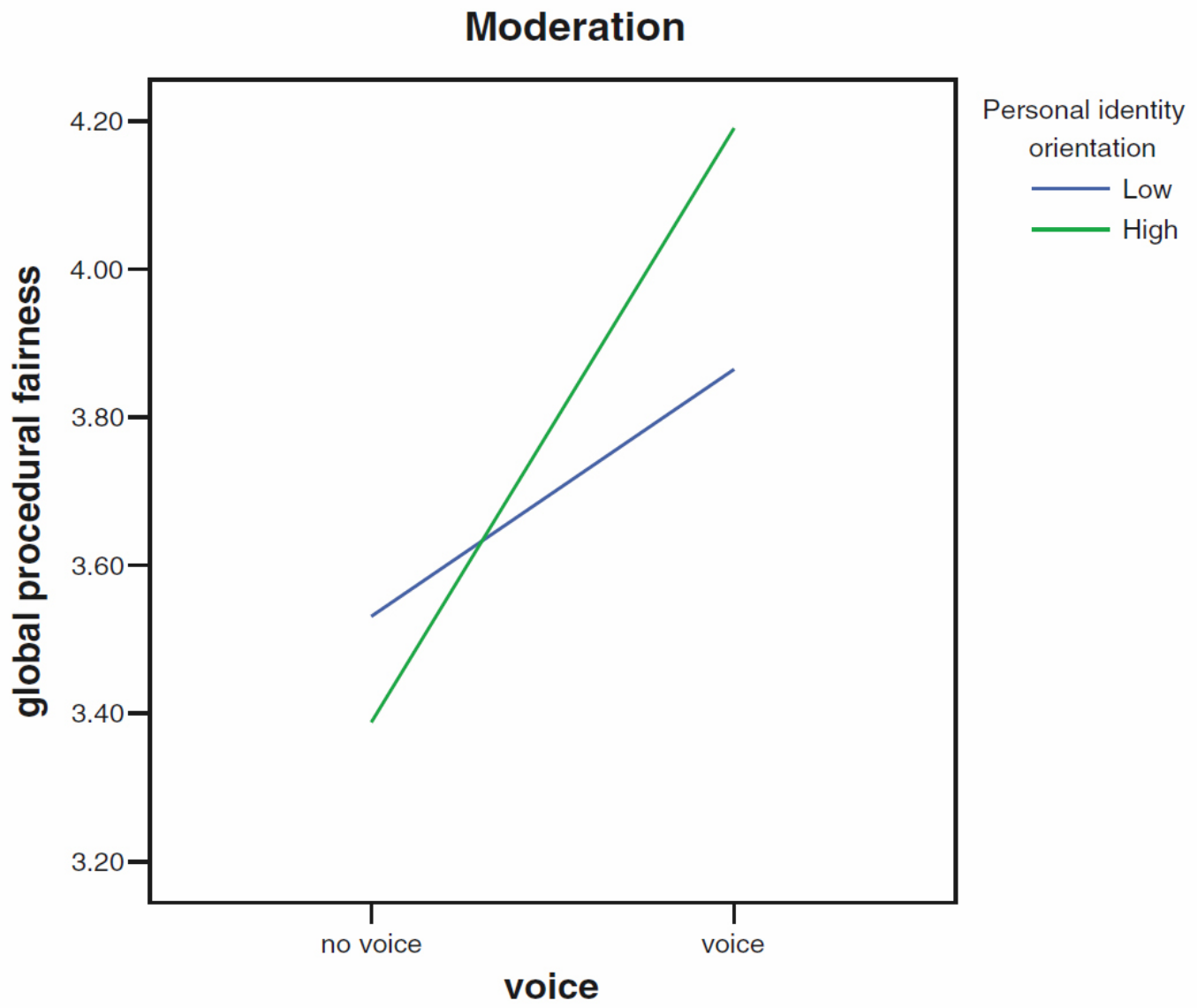

Fig. 1 Personal identity orientation moderates the relationship between voice and global procedural fairness. Those with a strong personal identity orientation showed a more pronounced voice effect than those with a lower personal identity orientation

means that the participants who viewed the situation as providing greater opportunity for their input reported less negative emotional response. In turn, negative emotional response was negatively related to ratings of GPF, $r(279)=-0.55, p<0.001$. Thus, the more negative emotional response, the less fair the participants viewed the conflict. Finally, the voice subscale and ratings of GPF were positively correlated, $r(283)=$ $0.713, p<0.001$.

Across the entire sample, mean scores were higher for personal identity $(\mathrm{M}=4.31, \mathrm{SD}=0.52)$ than for collective identity $(\mathrm{M}=3.31, \mathrm{SD}=0.69)$ or social identity $(\mathrm{M}=3.43, \mathrm{SD}=0.70)$. Using mean scores for identity orientation, $83 \%$ of the current sample had their highest score on personal identity, approximately $10 \%$ had their highest score on social identity, and 3.5\% had their highest score in collective identity. The remaining $3.5 \%$ had equal means on 2 or all 3 of the identity orientations.
Because the majority of our sample was highly personally oriented, we focused our attention on the subtle differences in the identity orientations. First, we divided the participants into high or low personal identity based on the sample median. A 2-factor analysis of variance was conducted to determine if personal identity moderated voice and global procedural fairness. As described by Baron and Kenny (1986), a dichotomous independent variable's effect on the dependent variable may vary as a function of a dichotomous moderator variable. This moderator effect is revealed by an interaction. In the current study, the main effect for voice was significant, $F(1,279)=35.33, p<0.001$ and the interaction was also significant, $F(1,284)=6.02, p=$ 0.015 . While both the groups of participants rated the voice scenario as significantly more fair than the no voice scenario, the difference was more pronounced in those with high personal identity orientations than those with low personal identity orientations. Those 
with low personal identity orientations rated the voice situation slightly higher in global procedural fairness $(\mathrm{M}=3.86)$ than the no voice situation $(\mathrm{M}=3.53)$. However, those with high personal identity orientations rated the voice situation much higher in global procedural fairness $(\mathrm{M}=4.19)$ than the no voice situation $(\mathrm{M}=3.39)$. This relationship is illustrated in Figure 1. This indicates that voice is even more important in perceptions of fairness for adolescents with high personal identity orientation than it is for adolescents with low personal identity orientation.

Complementary analyses revealed that collective identity and social identity did not have moderating effects in the same way as personal identity. Main effects were consistently found for voice but not for collective identity or social identity ( $F<1$ for both) and the relevant interactions were not significant ( $F<1$ for both).

Negative Emotional Response, Voice, and Global Procedural Fairness

As shown in Table I and Figure 2, negativeemotional response was investigated as a possible mediator between voice and global procedural fairness using four regression analyses as outlined by Baron and Kenny (1986). First, the dependent variable was regressed on the independent variable (path C). In this case, voice significantly predicted appraisals of global procedural fairness, $\beta=0.713, t(282)=17.033, p<0.001$. Higher scores on the voice subscale were related to higher levels of global procedural fairness. Voice also accounted for a significant portion of variance in global procedural fairness, $R^{2}=0.508, \mathrm{~F}(1,281)=290.12, p$ $<0.001$. Next, the mediator was regressed on the independent variable (path A). In this case, negative emotional response was regressed on voice, resulting in a significant relationship, $\beta=-0.646, t(282)=-14.147$, $p<0.001$. Higher scores on the voice subscale were related to lower levels of negative emotional response. Voice accounted for a significant amount of variance in negative emotional response, $R^{2}=0.417, F(1,281)$

Table I. Testing Negative Emotional Response as a Mediator for Voice and Global Procedural Fairness

\begin{tabular}{lccc}
\hline \multicolumn{1}{c}{ Model } & $B$ & $\beta$ & $t$ \\
\hline (1) Path C: Global procedural & 0.596 & 0.713 & $17.03^{* *}$ \\
$\quad$ fairness on voice & & & \\
(2) Path A: Negative emotional & -0.697 & -0.646 & $-14.147^{* *}$ \\
$\quad$ response on voice & & & \\
(3) Path B: Global procedural & -0.422 & -0.543 & $-10.833^{* *}$ \\
$\quad$ fairness on negative emotional \\
$\quad$ response
\end{tabular}

$=200.14, p<0.001$. Next, the dependent variable was regressed on the mediator (path B). Negative emotional response significantly predicted appraisals of global procedural fairness, $\beta=-0.543, t(282)=-10.833$, $p<0.001$. Higher levels of negative emotional response were related to lower appraisals of global procedural fairness. Negative emotional response accounted for a significant amount of variance in global procedural fairness, $R^{2}=0.295, F(1,281)=117.348, p<0.001$. Finally, the dependent variable is regressed on both the independent variable and the mediator to determine whether the effect of the independent variable is reduced when controlling for the mediator (path C) and whether the effect of the mediator remains significant when controlling for the independent variable.

In this case, the effect of voice on global procedural fairness was reduced, $\beta=0.620, t(282)=11.416$, $p<0.001$. Because this relationship was still significantly different from 0 , full mediation was not supported. A follow-up comparison of the unmediated regression coefficient and the mediated regression coefficient using the Sobel test was significant, $t=$ $8.61, p<0.001$, indicating that the inclusion of negative emotional response significantly reduced the relationship between voice and global procedural fairness. This result is consistent with the hypothesis of partial mediation as displayed in Figure 2. The relationship between negative emotional response and global procedural fairness remained significant when controlling for voice, $\beta=-0.143, t(282)=-2.632, p=0.009$.

\section{Discussion}

In recent years, there have been considerable advances in our understanding of the psychology of procedural justice, particularly in the family context. Nonetheless, a comprehensive explanation for why individuals' procedural justice judgments influence their reactions in given situations is still incomplete. In an attempt to contribute to that explanation, the current study had 3 goals. First, we sought to determine whether having voice in family decision making influences appraisals of global procedural fairness by older adolescents. Second, we wanted to examine the importance of identity orientation in procedural justice judgments. Third, we wanted to examine the link between justice appraisals and affective arousal.

In line with earlier procedural justice research, we were able to elicit a strong main effect for the voice manipulation. In the current study, the voice manipulation involved a very slight difference in wording. Nonetheless, it is clear that this minor wording variation made a great difference to our participants. Partic- 


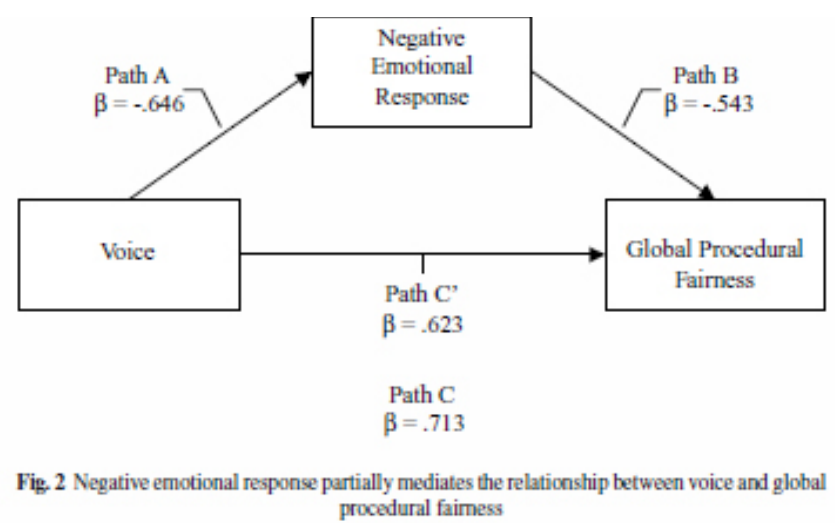

ipants of all ethnic backgrounds clearly felt that they had less opportunity to express themselves in the no voice condition. The participants in the no voice condition viewed the situation as much less fair than those who were told that their parents had considered their point of view. Before considering this finding in conjunction with participants' identity orientation and emotional response, it is important to discuss some possible implications of the voice effect in the context of family relationships among older adolescents.

Barrett-Howard and Tyler (1986) have suggested that intermediate emotional bonds (rather than very strong ones or very weak ones) lead to greater concern for procedural fairness (Barrett-Howard and Tyler, 1986). It is precisely during the period of late adolescence when students strive to strike a balance between maintaining needed emotional support and resources from family and their increasing push for autonomy and independence. Thus, late adolescence may be a period in the life cycle where issues of procedural justice are particularly salient, especially from the viewpoint of the student. It was clear in the present study that the older adolescents cared very deeply about the procedural protections they were afforded. The mere fact that parents were willing to consider their views before making a decision elicited significantly higher ratings of procedural fairness.

Leventhal (1980) may have shed some light on this issue from a different vantage point when he stated

As a child's range of contacts expands, experience is gained in other social settings and the conceptions of procedural and distributive fairness that prevails in those settings may be somewhat different from those at home. To the extent that the child internalizes these new rules, the justice judgment sequence is likely to be aroused when the child returns to the family. Procedures and distributions which, heretofore, were accepted uncritically may be subject to searching evaluation because they are inconsistent with standards newly acquired in other social settings.
Consistent with this view, our adolescents were all students at a large university who were likely to be experiencing an expanding range of social contacts and settings. To the extent that those contacts and settings encouraged voice and participation in decision making, as one might expect in a university environment, older adolescents may then have expected similar treatment by parents and may have reacted accordingly, depending on whether they were in the voice or no voice condition.

In addition to voice, personal identity orientation appears to be an important aspect of the procedural fairness judgment process within the family context. In this study, personal identity was shown to moderate the relationship between voice and procedural fairness judgments.

As Skitka (2003) noted, justice research has primarily focused on social identity in relation to procedural justice judgments and has relatively ignored other identity orientations. On the basis of the current research, personal identity orientation clearly needs to be considered as well. Personal identity orientation (as opposed to social or community) was highly prevalent among our participants from varied ethnic backgrounds. This could be partly because the scenario dealt with grades and financial support, which could have primed achievement concerns that are relevant to personal identity. It is also possible that personal identity orientation is stronger than other possible identity orientations in an older adolescent college population.

Even without a distribution across all 3 identity orientations, a moderator effect was still detected. By dividing participants into groups of high versus low personal identity orientation using a median split, we were able to test for moderator effects based on strength of personal identity orientation. As a result, personal identity orientation proved to be a very useful moderator variable in describing the relationship between voice and procedural fairness judgments. This moderator effect was expressed as an interaction between the voice manipulation and the level (high versus low) of personal identity orientation. Participants with higher 
personal identity orientations were more strongly affected by the voice manipulation than participants with lower personal identity orientations. They rated the voice condition as more fair and the no voice condition as less fair than did the participants with lower personal identity orientations. This may be because adolescents with higher levels of personal identity orientation find voice to be a more important component of procedural justice and reacted more strongly when they were not given the opportunity for voice. Further research involving participants of various ages and with different life experiences may enable us to investigate the effect of other possible identity formations on justice judgments.

The findings also indicated that negative emotional response partially mediated the relationship between voice and global judgments of procedural fairness. That is, negative emotional response partially accounts for the strong relationship between availability of voice and fairness judgments. As expressed by Baron and Kenny (1986), a mediator explains how external physical events take on internal psychological significance. In the current situation, parental unwillingness to allow for voice was associated with negative emotional response in the adolescent, which in turn was associated with lower ratings of procedural fairness. Krehbiel and Cropanzano (2000) have outlined the importance of emotional factors in justice judgments. As they stated, emotions often encourage a person to act in a certain way. Emotional state may be one of the determining factors in the outward reaction to procedural injustice, which, in older adolescents, may include deviant and aggressive behavior (Fondacaro et al., 1998). This link between affective arousal and procedural justice is a key contribution to the current body of research and warrants further investigation.

In response to some earlier procedural justice findings, Sears (1986) noted that college students may be different from the general population because they are typically more cognitively and verbally oriented and may view control over the opportunity to present evidence and arguments as a particularly key feature of procedural justice. This "college student voice effect" may have contributed in part to the strength of the voice main effect in the current study. Future research should address this issue by utilizing older adolescents who are not in a college setting.

Notwithstanding the noted limitations, our study does demonstrate the importance of providing opportunities for voice within families with older adolescents. It is clear that older adolescents value having a chance to voice their opinions during decisions even when they are residing away from home. This finding is consistent with research asserting that late adoles- cence is a transitional time period in which individuals work to retain close family ties even while gaining a new level of autonomy. The link between identity orientation and procedural justice appraisals is a new finding that warrants further investigation. The connection between voice and global appraisals of fairness was particularly strong in adolescents who had high levels of personal identity orientation. In light of the current findings, it also seems that those with high personal identity orientations may react quite strongly to being denied voice in decisions and subsequently rate situations without voice as much less fair. Since low appraisals of fairness within the family have been linked to deviant behavior and psychosocial problems (Fondacaro et al., 1998), this finding presents an important area for future study.

\section{Appendix A: Conflict Scenario}

\section{The no-voice condition:}

Directions: Imagine that the conflict situation described below actually happened to you. Read the situation carefully, try to imagine yourself in the situation, and then use the items that follow to rate the conflict situation on a 5-point scale, ranging from 1 (strongly disagree) to 5 (strongly agree).

You are a sophomore at UF. You and your parents have agreed that they will financially support you if you maintain a 3.0 GPA each semester. You have done so for your freshman year. However, for the first semester of your sophomore year, you begin to attend latenight keg parties, and your grades suffer. Your GPA drops to a 2.0. Your parents are willing to give you a second chance before they cut you off. For the second semester, you work harder and bring your GPA up to a 2.8. You are prepared to explain to your parents before they make their decision that you are taking harder classes, doing volunteer work, having roommate problems, and that a 2.8 is close to a 3.0. However, they make their decision about whether to continue supporting you financially without listening to your arguments.

The voice condition:

Directions: Imagine that the conflict situation described below actually happened to you. Read the situation carefully, try to imagine yourself in the situation, and then use the items that follow to rate the conflict situation on a 5-point scale, ranging from 1 (strongly disagree) to 5 (strongly agree).

You are a sophomore at UF. You and your parents have agreed that they will financially support you if you maintain a 3.0 GPA each semester. You have done 
so for your freshman year. However, for the first semester of your sophomore year, you begin to attend latenight keg parties, and your grades suffer. Your GPA drops to a 2.0. Your parents are willing to give you a second chance before they cut you off. For the second semester, you work harder and bring your GPA up to a 2.8. You are prepared to explain to your parents before they make their decision that you are taking harder classes, doing volunteer work, having roommate problems, and that a 2.8 is close to a 3.0. They make their decision about whether to continue supporting you financially after listening to your arguments.

\section{Appendix B: Questions from the Family}

\section{Decision Making Questionnaire}

\section{Voice Subscale}

1. Your parent(s) asked for your input before a decision was made.

18. Your parent(s) gave you an opportunity to express your side.

24. Your parent(s) carefully considered your views. 36. When your parent(s) made their decision, they gave little consideration to what you said.

57. You had a chance to discuss how you were being evaluated.

64. You felt as if your parent(s) listened to you.

\section{Global Procedural Fairness}

8. Looking back, the methods or procedures used to handle this situation were fair.

38. The rules or procedures followed were fair.

53. The methods, rules, or procedures followed in handling this situation were fair.

56. The approach or methods followed in handling this situation were very effective in making certain that everyone was treated fairly.

61. Overall, you were treated fairly.

67. Overall, your parent(s) tried to handle the situation fairly.

\section{References}

American Psychological Association (2002). Ethical principles for psychologists and code of conduct. Am. Psychol. 57(12): 1,0601,073 .

Baron, R. M., and Kenny, D. A. (1986). The moderator-mediator variable distinction in social psychological research: Conceptual, strategic, and statistical considerations. J. Pers. Soc. Psychol. 51: $1,173-1,182$.
Barrett-Howard, E., and Tyler, T. R. (1986). Procedural justice as a criterion in allocation decisions. J. Pers. Soc. Psychol. 50: 296-304.

Brockner, J., Heuer, L., Siegel, P. A., Wisenfeld, B., Martin, C., Grover, S., Reed, T., and Bjorgvinsson, S. (1998). The moderating effect of self-esteem in reaction to voice: Converging evidence from five studies. J. Pers. Soc. Psychol. 75: 394-407.

Cheek, J. M., and Tropp, L. R. (1994). The Aspects of Identity Questionnaire: History and Bibliography. Unpublished manuscript, Wellesley College, MA.

Clayton, S., and Opotow, S. (2003). Justice and identity: Changing perspectives on what is fair. Pers. Soc. Psychol. Rev. 7: 298-310.

Erikson, E. H. (1959). Identity and the life cycle. Psychol. Issues, 1 (Monograph No. 1).

Folger, R., and Konovsky, M. A. (1989). Effects of procedural and distributive justice on reactions to pay raise decisions. Acad. Manage. J. 32: 115-130.

Fondacaro, M. R., and Heller, K. (1990). Attributional style in aggressive adolescent boys. J. Abnorm. Child Psychol. 18: 75-89.

Fondacaro, M. R., Dunkle, M. E., and Pathak, M. K. (1998). Procedural justice in resolving family disputes: A psychosocial analysis of individual and family functioning in late adolescence. J. Youth Adolesc. 27: 101-118.

Fondacaro, M. R., Jackson, S. L., and Luescher, J. (2002). Toward the assessment of procedural and distributive justice in resolving family disputes. Soc. Justice Res. 15: 341-371.

Jackson, S., and Fondacaro, M. (1999). Procedural justice in resolving family conflict: Implications for youth violence prevention. Law \& Policy 21: 101-127.

James, W. (1890). The Principles of Psychology. Holt, Oxford.

Konovsky, M. A., and Cropanzano, R. (1991) The perceived fairness of employee drug testing as a predictor of employee attitudes and job performance. J. Appl. Psychol. 76: 698-707.

Korsgaard, M. A., Sapienza, H. J., and Schweiger, D. M. (1980). Beaten before begun: The role of procedural justice in planning change. J. Manage. 28: 497-516.

Krehbiel, P. J., and Cropanzano, R. (2000). Procedural justice, outcome favorability, and emotion. Soc. Justice Res. 15(4): 339-360.

Leung, K., and Lind, E. A. (1986). Procedure and culture: Effects of culture, gender, and investigator status on procedural preferences. J. Pers. Soc. Psychol. 50: 1,134-1,140.

Leventhal, G. S. (1980). What should be done with equity theory? New approaches to the study of fairness in social relationships. In Gergen, K., Greenberg, M., and Willis, R. (eds.), Social Exchange. Plenum, New York, pp. 27-55.

Lind, A. E. (1980). Procedure and outcome effects on reactions to adjudicated resolution of conflicts of interest. J. Pers. Soc. Psychol. 39: 643-653

Lind, E. A., and Tyler, T. R. (1988). The Social Psychology of Procedural Justice. Plenum, New York.

Marcia, J. E. (1980). Identity in adolescence. In Adelson, J. (ed.), Handbook of Adolescent Psychology. Wiley, New York, pp. 159- 187.

Matteson, D. R. (1975). Adolescence Today: Sex Roles and the Search for Identity. Homewood, Dorsey, IL.

Meilman, P. W. (1977). Crisis and Commitment in Adolescence: A Developmental Study of Ego Identity Status. Unpublished doctoral dissertation, University of North Carolina.

Mikula, G., Scherer, K. R., and Athenstaedt, U. (1998). The role of injustice in the elicitation of differential emotional reactions. Pers. Soc. Psychol. Bull. 24: 769-783.

Murphy-Berman, V., Cross, R., and Fondacaro, M. (1999). Fairness and health care decisions making: Testing the group value model of procedural justice. Soc. Justice Res. 12: 117-129.

Poythress, N. G., Schumacher, J., and Wiener, R. (1993). Procedural justice judgments of alternative procedures for resolving medical malpractice claims. J. Appl. Soc. Psychol. 23: 1,639-1,658.

Sears, D. O. (1986). College sophomores in the laboratory: Influences of a narrow data base on social psychology's view of human nature. J. Pers. Soc. Psychol. 51: 515-530. 
Skitka, L. J. (2002). Do the means always justify the ends, or do the ends sometimes justify the means? A value protection model of justice reasoning. Pers. Soc. Psychol. Bull. 28: 452-461.

Skitka, L. J. (2003). Of different minds: An accessible identity model of justice reasoning. Pers. Soc. Psychol. Rev. 7: 286-297.

Thibaut, J., and Walker, L. (1975). Procedural Justice: A Psychological Analysis. Erlbaum, Hillsdale, NJ.

Tyler, T. R. (1984). The role of perceived injustice in defendants' evaluations of their courtroom experience. Law Soc. Rev. 18: 51-74.

Tyler, T. R. (1988). What is procedural justice? Criteria used by citizens to assess the fairness of legal procedures. Law Soc. Rev. 22: 103-135.

Tyler, T. R. (1994). Psychological models of justice motive: Antecedents of distributive and procedural justice. J. Pers. Soc. Psychol. 67: 850- 863
Tyler, T. R., and Blader, S. L. (2003). The group engagement model: Procedural justice, social identity, and cooperative behavior. Pers. Soc. Psychol. Rev. 7: 349-361.

Tyler, T. R., Boeckmann, R. J., Smith, H. J., and Huo, Y. J. (1997). Social Justice in a Diverse Society. Westview Press, Oxford.

Tyler, T. R., and Caine, A. (1981). The influence of outcomes and procedures on satisfaction with formal leaders. J. Pers. Soc. Psychol. 41: 642-655.

Tyler, T. R., and Folger, R. (1980). Distributional and procedural aspects of satisfaction with citizen-police encounters. Appl. Soc. Psychol. 1: 81-292.

Tyler, T. R., and Lind, E. A. (2001). Procedural Justice. In Sanders, J., and Hamilton, V. L. (eds.), Handbook of Justice Research in Law. Kluwer Academic/Plenum Publishers, New York. 